\title{
Nivolumab-induced posterior reversible encephalopathy syndrome
}

Haitham M. Hussein, MD, MSc; Bradleigh Dornfeld, MD; Daniel J. Schneider, MD

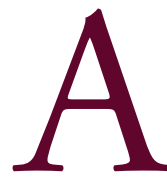

47-year-old woman with metastatic, poorly differentiated lung cancer with neuroendocrine features was brought to the hospital after 4 days of nausea, vomiting, disorientation, and 1 generalized tonic clonic seizure. On examination, her blood pressure was $148 / 95 \mathrm{~mm} \mathrm{Hg}$, heart rate $95 \mathrm{bpm}$, and temperature $36.4^{\circ} \mathrm{C}$. She was encephalopathic and had cortical blindness. She had no history of seizures or visual impairment. MRI brain without contrast showed changes consistent with posterior reversible encephalopathy syndrome (PRES; figure, A). She had been on nivolumab, of which she had

Figure Fluid-attenuated inversion recovery-weighted MRI
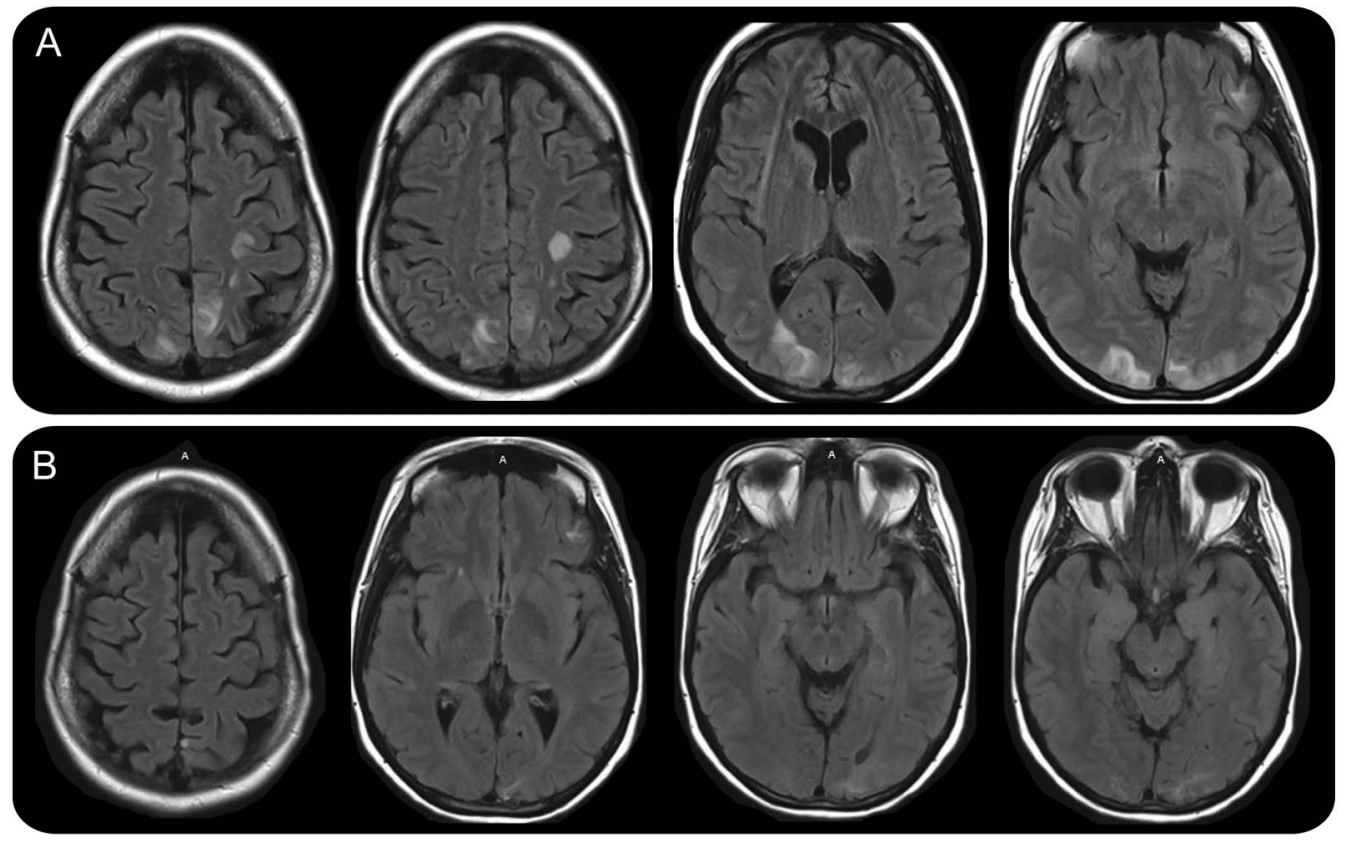

Initial study (A) showed cortical and subcortical hyperintense signal in the posterior aspect of hemispheres, involving bilateral frontal, parietal, and occipital lobes, bilateral thalami, and left temporal lobe. Nine-month follow-up study (B) showed incomplete resolution of posterior reversible encephalopathy syndrome lesions with small areas of gliosis and encephalomalacia in the bilateral occipital lobes, left parasagittal parietal lobe, and left inferior frontal and left superior temporal lobes.

Regions Hospital Comprehensive Stroke Center (HMH), St Paul; Hennepin County Medical Center (BD), Minneapolis; and HealthPartners Clinics and Services (DJS), St Paul, MN.

Funding information and disclosures are provided at the end of the article. Full disclosure form information provided by the authors is available with the full text of this article at Neurology.org/cp.

Correspondence to: Haitham.M.Hussein@healthpartners.com 
received 2 doses; the last dose was 24 days before the onset of this illness. She had not received any other cancer-directed therapy for 6 months. She did not have any other cause of PRES (pregnancy, severe hypertension, sepsis). The patient was treated with supportive therapy and returned to baseline mental state and vision after a few weeks. However, she developed a seizure disorder with a focal onset in the form of stereotyped visual hallucinations of primary colors in a geometrical arrangement and secondary generalization. Repeat MRI with contrast 3 and 9 months later showed incomplete resolution of PRES lesions, with residual cortical/subcortical nonenhancing gliosis seen in bilateral occipital poles and left frontotemporal area (figure, B).

Nivolumab is one of the monoclonal antibody agents that targets programmed death receptor 1 (PD-1) and is used in malignancy. Anti-PD-1 agents enhance the antitumor activity of the immune system by inhibiting the negative regulatory signaling from $\mathrm{T}$ cells. Other anti-PD-1 agents have been reported to cause PRES. ${ }^{1,2}$

\section{REFERENCES}

1. LaPorte J, Solh M, Ouanounou S. Posterior reversible encephalopathy syndrome following pembrolizumab therapy for relapsed Hodgkin's lymphoma. J Oncol Pharm Pract 2017;23:71-74.

2. Maur M, Tomasello C, Frassoldati A, Dieci MV, Barbieri E, Conte P. Posterior reversible encephalopathy syndrome during ipilimumab therapy for malignant melanoma. J Clin Oncol 2012;30: e76-e78.

Received December 17, 2016. Accepted in final form March 22, 2017.

\section{AUTHOR CONTRIBUTIONS}

H. Hussein: drafting/revising the manuscript, study concept or design. B. Dornfeld: drafting/revising the manuscript. D. Schneider: drafting/revising the manuscript.

\section{STUDY FUNDING}

No targeted funding reported.

\section{DISCLOSURES}

H. Hussein serves as Editor of the Resident \& Fellows Section, Journal of Neuroimaging, and on the editorial board of Neurology: Clinical Practice. B. Dornfeld and D. Schneider report no disclosures. Full disclosure form information provided by the authors is available with the full text of this article at Neurology.org/cp.

\section{Practical Implications}

Neurology ${ }^{\circledR}$ Clinical Practice is committed to providing clinical insights that are helpful to neurologists in everyday practice. Each Full Case will include a "Practical Implications" statement, a pearl of wisdom for the practicing clinician. 